\title{
Development of Fractal Pattern Making Application using L-System for Enhanced Machine Controller
}

\author{
Alexander A S Gunawan ${ }^{1}$, Jimmy Linggarjati ${ }^{2}$, and Yandi Wijaya ${ }^{1}$ \\ ${ }^{1}$ Mathematics Department, School of Computer Science, Bina Nusantara University, Jakarta, Indonesia \\ ${ }^{2}$ Computer Engineering Department, Bina Nusantara University, Jakarta, Indonesia \\ Sent offprint requests to: aagung@binus.edu
}

\begin{abstract}
One big issue facing the industry today is an automated machine lack of flexibility for customization because it is designed by the manufacturers based on certain standards. In this research, it is developed customized application software for CNC (Computer Numerically Controlled) machines using open source platform. The application is enable us to create designs by means of fractal patterns using L-System, developed by turtle geometry interpretation and Python programming languages. The result of the application is the G-Code of fractal pattern formed by the method of L-System. In the experiment on the CNC machine, the G-Code of fractal pattern which involving the branching structure has been able to run well.
\end{abstract}

\section{Introduction}

Smid [1] stated that the CNC (Computer Numerically Controlled) machines are the development of manual machines which using a microprocessor to control it. $\mathrm{CNC}$ machine itself is a machine tool which is capable of automatically forming a pattern of computer-assisted design. The CNC machines use command code of the computer and no longer use human power to run it.

Equipped by CAM (Computer Aided Manufacturing) software, CNC machines can make the drawing design of objects, created by the help of CAD software (Computer Aided Design). Nevertheless Bovill [2] stated in conceptual design stage, the initial design stage, in which the process is characterized by uncertain idea, CAD (Computer Aided Design) is rarely used application. At the conceptual design stage, designers usually create many ideas and turn it into a drawing sketch by only the help of a paper and pencil. CAD (Computer Aided Design) is rarely used at this stage because it requires a complete definition, concrete, and precise for geometric design that is usually done at a later stage. Therefore, it should be sought the solution to integrate the conceptual design stage with CAD software to create drawing sketch of desired design using computer directly.

One solution, proposed by Soo [3], is integration of the conceptual design stage with CAD into one application software. This solution is come from the observation that many jewellery products are adopting attractive pattern of natural objects, which can be designed by fractal geometry. The proposed solution by Soo [3] is only for rapid prototyping, which the fractal geometry implemented using Iterated Function System, and the solutions have not been implemented in application software.

To generate the fractal design patterns, actually many methods that can be applied, one of them is L-System method, which can be implemented easily in programming by the help of the turtle geometry interpretation. By above reasoning, this research is intended to developing customized application software for $\mathrm{CNC}$ machines which can be used to create design patterns using fractal geometry automatically based on input from users.

\section{Enhanced Machine Controller}

Enhanced Machine Controller or abbreviated as EMC ref. [4] is computer software for controlling $\mathrm{CNC}$ machines such as milling machines, lathes, plasma cutters, cutting machines, robots, hexapods, and others. EMC is open source software which licensed under GNU General Public License and GNU Lesser General Public License (GPL and LGPL).

EMC2 is the progress of EMC software. There are four major components to the EMC2 software, namely: motion controller, controller $\mathrm{I} / \mathrm{O}$ discrete modules to coordinate controllers and graphical user interface. And especially in EMC2, there is a facility called the HAL (Hardware Abstraction Layer) ref. [5] which allows adjustment without recompiling EMC2 configuration so that it will simplify the interface to the hardware. Because of the nature of open source, the EMC2 facilitate the 
customization process for developing specific application software.

Figure 1 shows a simple block diagram showing the EMC2 system for 3-axis machine. The diagram shows the stepper motor system. PC with Linux as the operating system is used to control the stepper motors drive by sending a signal through the printer port (parallel). The signals (pulses) make the drive stepper motors moving.

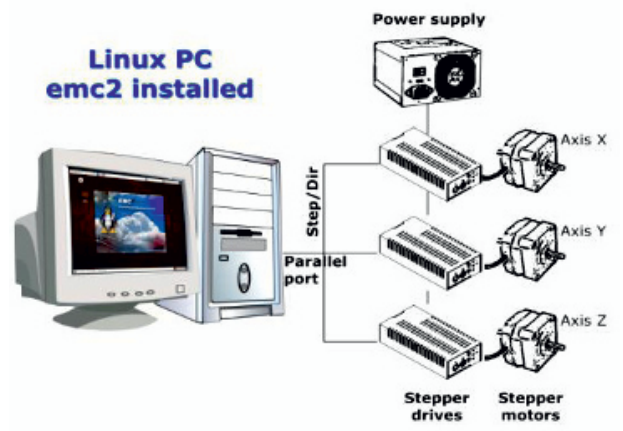

Fig. 1. EMC2 Controlled Machine

\subsection{AXIS Interface}

AXIS interface is one of the display interfaces of EMC2. AXIS is the default interface to EMC2 which is actively developed by its users. AXIS interface can be reconfigured by adding the Virtual Control Panel to adjust the shape of the display when running the EMC2 program to suit the needs of the user. AXIS can be seen in figure 2 below:

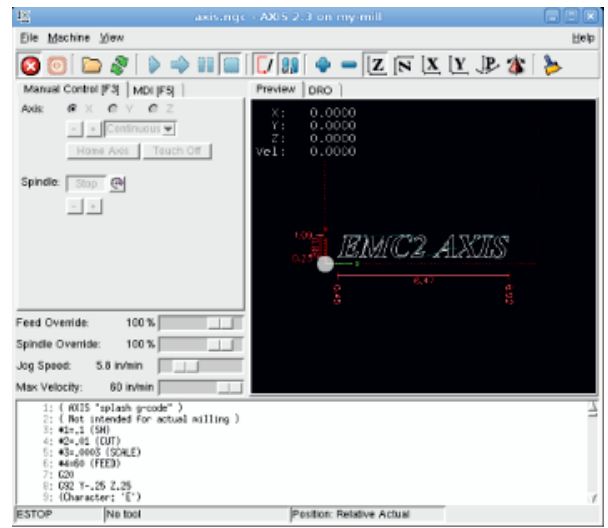

Fig. 2. AXIS Interface

\subsection{Python Programming Language 2.6}

Application software for L-System methods is developed using Python programming language 2.6. Python run on EMC2-AXIS over Ubuntu Linux operating system. Python ref. [6] is a dynamic programming language that supports object-oriented programming. In addition, the language is easy to use because it has a clear structure and grammar and also has extensive libraries. Besides Python language can be integrated with other languages such as $\mathrm{C} / \mathrm{C}++$ and Java.

\subsection{G-Code}

G-Code ref. [4] is a programming language for $\mathrm{CNC}$ machine which is closely related to graphics and vector. This language is used as a connector between the machine tool and $\mathrm{CNC}$ software that resides on computer. The machine will follow the movements of the design which written in G-Code. G-Code programming language is written in a file with the extension *.ngc (Numerical GCode). Here are some examples of G-Code language along with their respective functions:

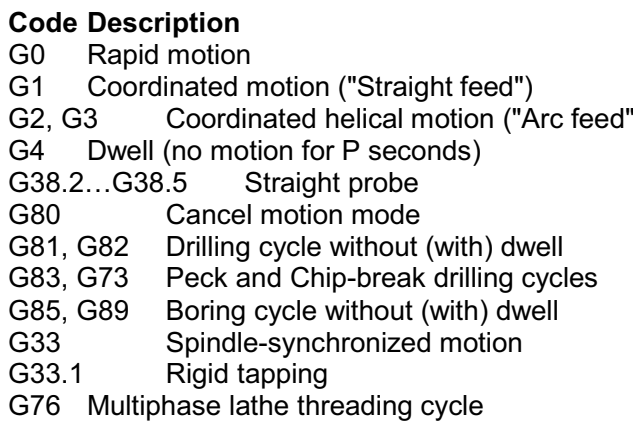

\subsection{Specification of CNC Machines}

Specification of the used CNC machines is as follows:

$\begin{array}{ll}\text { Minimum Track Width } & 0.5 \mathrm{~mm} \\ \text { Minimum Isolation Width } & 0.5 \mathrm{~mm} \\ \text { Minimum Drill Hole Diameter } & 0.6 \mathrm{~mm} \\ \text { Working Area (X/Y/Z) } & 500 \mathrm{~mm} \text { x } 400 \mathrm{~mm} \text { × } 50 \mathrm{~mm} \\ \text { Resolution } & 0.1 \mathrm{~mm} \\ \text { Travel speed (max) } & 200 \mathrm{~mm} \text { per second } \\ \text { X positioning system } & \text { dc-servo motor } \\ \text { Y/Z positioning system } & 5 \text {-phase stepper motors } \\ \text { Dimensions (W x H x D) } & 600 \mathrm{~mm} \times 500 \mathrm{~mm} \text { x } 1500 \mathrm{~mm} \\ \text { Weight } & 300 \mathrm{~kg} \\ \text { Power supply } & 220 \mathrm{~V}, 60 \mathrm{~Hz} / 500 \mathrm{VA}\end{array}$

The used $\mathrm{CNC}$ machine can be seen in figure 3 below:

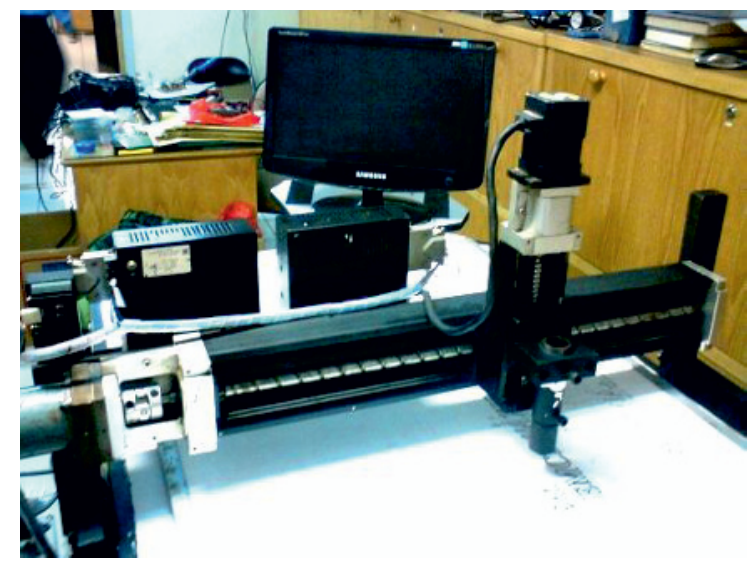

Fig. 3. The used CNC machine 


\section{L-System Methods}

According to Mandelbrot [7], fractal derived from the Latin adjective "fractus" which means crushed or cracked and then he defines a fractal as "the set which the Hausdorf dimension exceed its topological dimension". L-System is one of techniques for implementing fractals. Furtehrmore Prusinkiewicz [8] explains that the main concept of the L-System is rewriting. Rewriting mechanism in the L-System was introduced by Aristid Lindenmayer in 1968. The L-System consists of: symbols which can be used to create string, collection of production rules for transforming symbols to string, initial string value for the start of construction called as Axiom, and mechanism for translating the resulting string into the geometric structure. For the translation stage to the geometric structure, the developed application use turtle geometry interpretation ref. [9].

\subsection{Turtle Geometry}

Prusinkiewicz [8] explain that the turtle is defined as a triplet $(\mathrm{x}, \mathrm{y}, \alpha)$ where the Cartesian coordinates $(\mathrm{x}, \mathrm{y})$ represents the position of the turtle and the angle $\alpha$ indicates the direction for the turtle. If given step length $\mathrm{d}$ and angle $\delta$, the turtle can interpret the symbols in Table 1 below:

Table 1. Interpretation Turtle Table

\begin{tabular}{|c|l|}
\hline Symbol & \multicolumn{1}{|c|}{ Interpretation } \\
\hline $\mathrm{F}, \mathrm{X}$ & $\begin{array}{l}\text { Moving forward as d steps. } \\
\text { Status of the turtle turned into } \\
\left(\mathrm{x}^{\prime}, \mathrm{y}^{\prime}, \alpha\right), \text { where } \mathrm{x}^{\prime}=\mathrm{x}+\mathrm{d} \cos \alpha \\
\text { and } \mathrm{y}^{\prime}=\mathrm{y}+\mathrm{d} \sin \alpha . \text { Line } \\
\text { between the point }(\mathrm{x}, \mathrm{y}) \text { and }\left(\mathrm{x}^{\prime},\right. \\
\left.\mathrm{y}^{\prime}\right) \text { is drawn. }\end{array}$ \\
\hline $\mathrm{f}$ & $\begin{array}{l}\text { Moving Forward as d steps } \\
\text { without drawing a line. }\end{array}$ \\
\hline+ & $\begin{array}{l}\text { Rotates to the left as } \delta . . \text { The next } \\
\text { status turtle to }(\mathrm{x}, \mathrm{y}, \alpha+\delta) . \\
\text { Positive orientation is rotated } \\
\text { clockwise. }\end{array}$ \\
\hline- & $\begin{array}{l}\text { Rotates to the right as } \delta . . \text { The } \\
\text { next status turtle to }(\mathrm{x}, \mathrm{y}, \alpha-\delta) .\end{array}$ \\
\hline
\end{tabular}

According to the above rules, the turtle interprets the character string as a sequence of line segments. However, the plant or tree pattern is dominated by the branching structure ref. [8], so that two new symbols are introduced to define a branch that is '[' and ']' which their means described in Table 2:

Table 2. Interpretation of Symbol '[' and ']'

\begin{tabular}{|c|l|}
\hline Symbol & \multicolumn{1}{|c|}{ Interpretation } \\
\hline[ & $\begin{array}{l}\text { Saving the current position and } \\
\text { starting a new branch. }\end{array}$ \\
\hline$]$ & $\begin{array}{l}\text { Retrieving the last saved position } \\
\text { and moving again from there. }\end{array}$ \\
\hline
\end{tabular}

In addition to the symbols contained in Table 1 and Table 2 , the turtle will not interpret into anything and just stand still when seeing the other symbols.

\section{Implementation}

For the implementation of the application software requires several steps ref. [10]:

1. Developing Virtual Control Panel, integrated with AXIS through PyVCP. This step produces a file with the extension *.xml

2. Connecting PyVCP with EMC2 through the facilities of HAL (Hardware Abstraction Layer). This step results in file with extension *.hal

3. Resetting the configuration file axis mm.ini of $\mathrm{CNC}$ machine in order to read the *.xml and *.hal files, produced in (1) and (2). Modification is performed on PYVCP and POSTGUI_HALFILE.

4. Developing the L-System program in the Python programming language, which generate G-Code in a file with the extension *.ngc

5. Executing *.ngc file from AXIS Interface.

These steps are explained further in the following section:

\subsection{Developing Virtual Control Panel}

Developing the L-System GUI as in figure 4 required creation *.xml file to set the GUI display. PyVCP (Python Virtual Control Panel) is required to perform a virtualization panel on EMC2. The virtualization panel is needed because EMC2 only recognize the panel as an object. In our approach, the virtualization panel developed by PyVCP is used as connector between the EMC2 to the main program of L-System. Modification related this step in *.xml file is by adding <pyvcp $>$ tag and closed with the $</$ pyvcp $>$ tag.

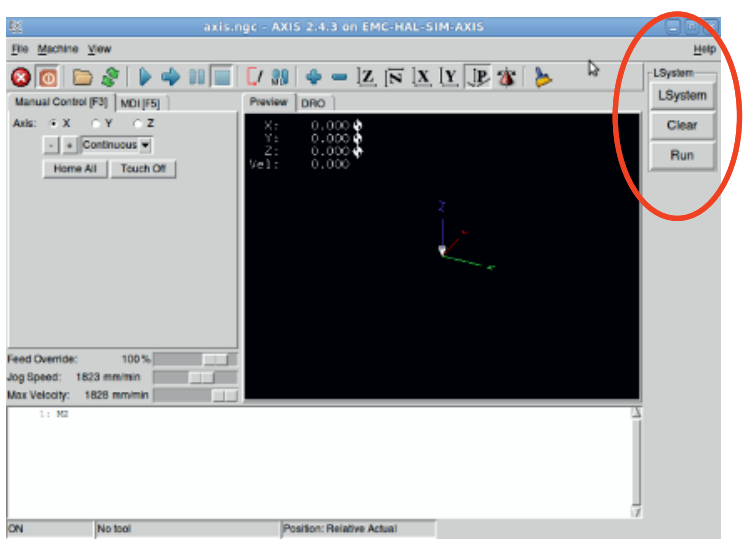

Fig. 4. L-System GUI

\subsection{Connecting PyVCP with EMC2 using HAL (Hardware Abstraction Layer)}

HALUI (Hardware Abstraction Layer User Interface) is a function in EMC2 used to make a signal and port, so that the GUI made by PyVCP can connect with the $\mathrm{CNC}$ machine. For this purpose, it is created $*$.hal file in order 
to the connecting signal through specific ports on EMC2 can get to $\mathrm{CNC}$ machine.

\subsection{Resetting the configuration file of CNC machine}

In EMC2-Axis software, there is *.ini (initial) files which storing and calling all existing settings for initiating the EMC2-Axis software. This file can be accessed and modified by the user. For the implementation of the application software, it is used axis_mm.ini file and modifies this file. Modification is mainly intended to allow EMC2 software can read the *.xml and *.hal produced in previous steps. This modification is performed on PYVCP and POSTGUI_HALFILE.

\subsection{Developing the L-System Program}

L-System methods are implemented via Python programming language 2.6 in Ubuntu Linux operating system. In addition, it is used Tkinter ref. [11] for creating Python GUI to input the data on L-System. Further EMC2-Axis is calling a Python program through MDI facility commands on HALUI (Hardware Abstraction Layer) and then executes the G-Code command: M101 M199 (User-defined M-codes).

The L-System program generates file in the form of GCode (file with extension *.ngc). In the implementation, the L-System program is named as M101 and the result is 101.ngc file whose contents can be viewed as follows:

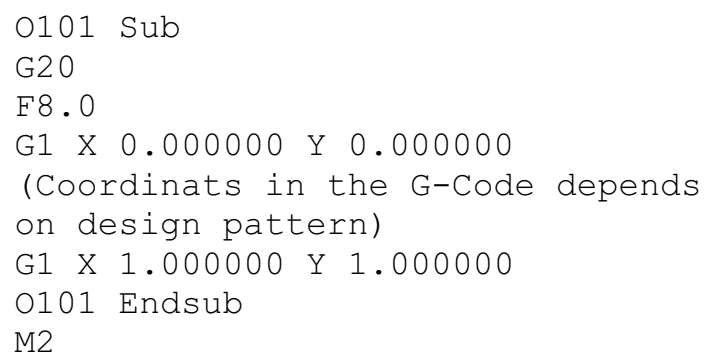

In figure 5, it can be seen L-System program developed with Python and Tkinter.

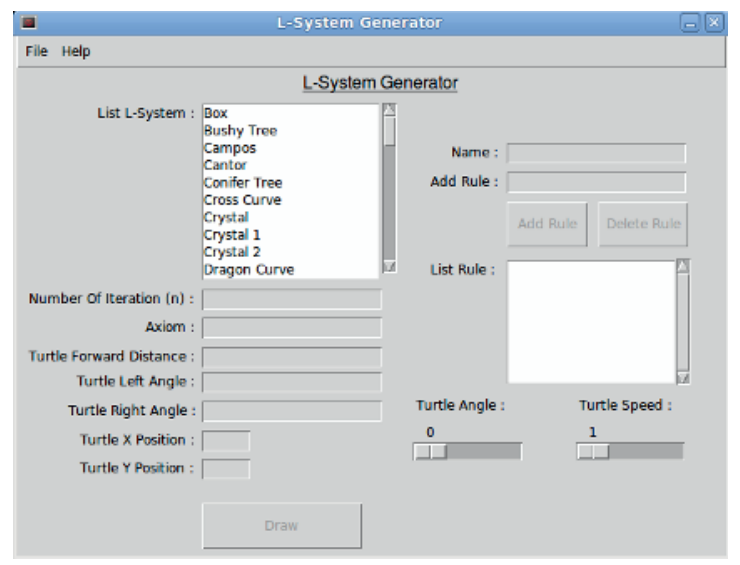

Fig. 5. L-System Program

\subsection{Executing G-Code from AXIS Interface}

After *.ngc which contains G-Code created then it can be invoked via MDI commands in HALUI (Hardware Abstraction Layer) and execute G-Code commands: O101 ... O199 (Call subroutines). To do this, the user can simply click the Run button in figure 4 L-System GUI.

\section{Results}

For simulation, there are eleven fractal design patterns for testing the application, which running well. The following table are some examples of fractal design patterns obtained after running L-System program using the specified rule in Table 3 below:

Table 3. Results of Program Testing

\begin{tabular}{ll}
\hline Fractals Type & Result \\
\hline $\begin{array}{l}\text { Box } \\
\text { Axiom: }\end{array}$ & F-F-F-F \\
Rule: & FF-F-F-F-FF
\end{tabular}

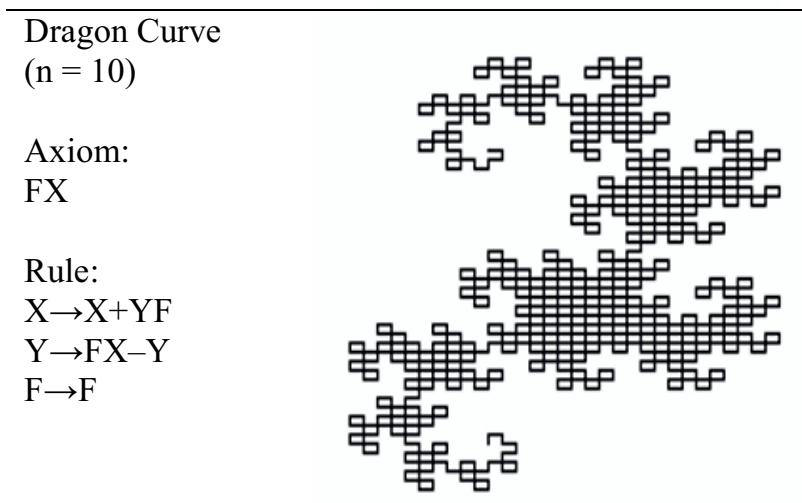

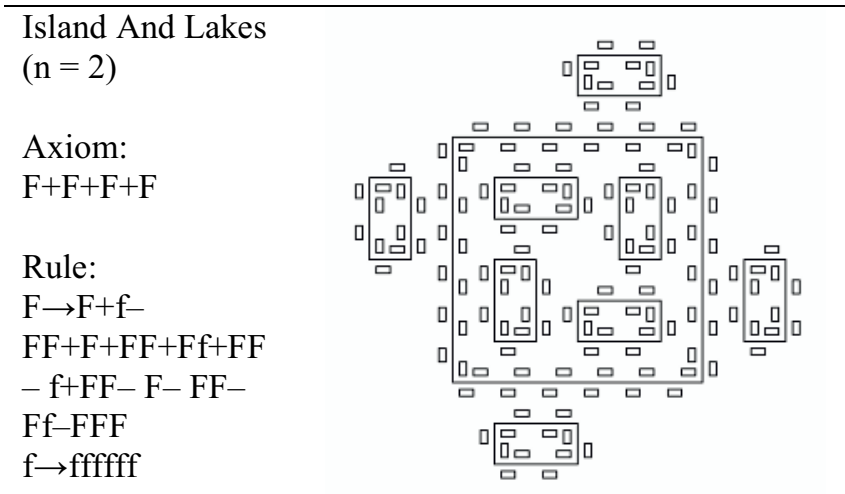

For testing in CNC Machine, it has been done three fractal design patterns, which have average time making about 9 minutes. Here in Table 4 is the result of fractal pattern, which involving the branching structure. It is obtained after L-System program running on the CNC machine that is: 
Table 4. Results from CNC Machine

\begin{tabular}{ll}
\hline Fractals Type & Result \\
\hline Bushy Tree \\
$(\mathrm{n}=3)$
\end{tabular}

\section{Conclusions}

From the results of the application software, some conclusions are obtained as follows:

a. EMC2 can be used to run CNC machines well and because it is open source, users can make the customization to adjust EMC2 according to their needs.

b. L-System methods with the help of turtle geometry interpretation can be used to form a fractal design patterns. The design patterns are useful in conceptual design stage which consuming time and cost.

\section{References}

1. P. Smid, CNC Programming Handbook $2^{\text {nd }}$ Edition, New York: Industrial Press Inc (2003)

2. C. Bovill, Fractal Geometry as Design Aid, Journal for Geometry and Graphics Volume 4 No 1, 71-78 (2000)

3. S.C. Soo, K.M. Yu, Rapid Prototyping Using Fractal Geometry, 424-431 (2001)

4. The EMC Team, User Manual $V \quad 2.4$. http://www.linuxcnc.org/docs/EMC2_User_Manual. $\operatorname{pdf}(2011)$

5. T. Starovešk, D. Brezak, T. Udiljak, D. Majetić, Implementation of A Linux-Based CNC Open Control System, 12th International Scientific Conference on Production Engineering - CIM (2009)

6. D. Ascher, A. Martelli, A. Ravenscroft, Python Cookbook, USA: O'Reilly (2005)

7. B.B. Mandelbrot, The Fractal Geometry of Nature, New York: W.H. Freeman And Company (1983)

8. P. Prusinkiewicz, A. Lindenmayer, The Algorithmic Beauty of Plants, New York: Springer-Verlag (2004)

9. I. Zammouri, B. Ayeb, Fractal Shapes Description with Parametric L-systems and Turtle Algebra,
World Academy of Science, Engineering and Technology 34 (2007)

10. A.A.S Gunawan, J. Linggarjati, Pengembangan Program Aplikasi Enhanced Machine Control dengan Python untuk Metode Interpolasi Newton, Jurnal ComTech, Vol 03 / No 01 / June 2012

11. J.W. Swipman, Tkinter 8.4 Reference: a GUI for Python, Mexico: New Mexico Tech (2010) 